Abstract

\title{
Morphology of Immature Stages of Sphaerophoria rueppellii (Wiedemann, 1830) (Diptera, Syrphidae) a Predator of Aphids Pest ${ }^{\dagger}$
}

\author{
José Javier Orengo Green ${ }^{1,}{ }^{*}$, Mariusz Kanturski ${ }^{2}$ and María Ángeles Marcos García ${ }^{1}$ \\ 1 Research Institute CIBIO (Centro Iberoamericano de la Biodiversidad). Science Park. University of Alicante. \\ San Vicente del Raspeig s/n. 03690-San Vicente del Raspeig (Alicante). Spain. \\ 2 Institute of Biology, Biotechnology, and Environmental Protection, Faculty of Natural Sciences, University \\ of Silesia in Katowice, Bankowa 9, 40-007 Katowice, Poland. \\ * Correspondence: jjog5@alu.ua.es \\ + Presented at the 1st International Electronic Conference on Entomology (IECE 2021), 1-15 July 2021; \\ Available online: https://iece.sciforum.net/.
}

Citation: Orengo Green, J.J.; Kanturski, M.; Marcos García, M.A. Morphology of Immature Stages of Sphaerophoria rueppellii (Wiedemann, 1830) (Diptera, Syrphidae) a Predator of Aphids Pest, in Proceedings of the 1st International Electronic Conference on Entomology, 1-15 July 2021, MDPI: Basel, Switzerland,

doi:10.3390/IECE-10377

Published: 30 June 2021

Publisher's Note: MDPI stays neutral with regard to jurisdictional claims in published maps and institutional affiliations.

Copyright: () 2021 by the authors. Submitted for possible open access publication under the terms and conditions of the Creative Commons Attribution (CC BY) license (http://creativecommons.org/licenses /by/4.0/).
The hoverfly Sphaerophoria rueppellii (Wiedemann, 1830) is widely distributed in the Palearctic, and their larvae prey on soft insect pests that cause significant agricultural losses. The correct morphological diagnosis of immature stages of natural enemies is especially important in biological control management. Little is known about the morphology of the immature stages of this predator, being only known the L3 stage using a light microscope, but lacking a complete study of the chaetotaxy. Here is provided a detailed and complete characterization of the three early stages of S. rueppellii using Scanning Electron Microscopy (SEM) with a special focus on the number, disposition, and functional morphology of the sensilla of the three immature stages. For the first time is described in detail the morphology of the Posterior Respiratory Process (PRP), as well as the chorionic sculpturing of the egg surface. An Energy-dispersive X-ray microanalysis (EDS) was performed to determine the composition of the principal components.

Keywords: hoverfly; taxonomy; puparium; egg; SEM 